\title{
Animal models in biological and biomedical research - experimental and ethical concerns
}

\author{
MONICA L. ANDERSEN ${ }^{1}$ and LUCILE M.F. WINTER ${ }^{2}$ \\ ${ }^{1}$ Departamento de Psicobiologia, Universidade Federal de São Paulo/UNIFESP, \\ Rua Napoleão de Barros, 925, 04024-002 São Paulo, SP, Brazil \\ ${ }^{2}$ Departamento de Fisiologia, Instituto de Biociências, Universidade de São Paulo/ \\ USP, Rua do Matão, Travessa 14, 05508-090 São Paulo, SP, Brazil \\ Manuscript received on March 28, 2017; accepted for publication on April 6, 2017
}

\begin{abstract}
How to cite: ANDERSEN ML AND WINTER LMF. 2019. Animal models in biological and biomedical research - experimental and ethical concerns . An Acad Bras Cienc 91: e20170238. DOI 10.1590/0001-3765201720170238.
\end{abstract}

\begin{abstract}
Animal models have been used in experimental research to increase human knowledge and contribute to finding solutions to biological and biomedical questions. However, increased concern for the welfare of the animals used, and a growing awareness of the concept of animal rights, has brought a greater focus on the related ethical issues. In this review, we intend to give examples on how animals are used in the health research related to some major health problems in Brazil, as well as to stimulate discussion about the application of ethics in the use of animals in research and education, highlighting the role of National Council for the Control of Animal Experimentation (Conselho Nacional de Controle de Experimentação Animal - CONCEA) in these areas. In 2008, Brazil emerged into a new era of animal research regulation, with the promulgation of Law 11794, previously known as the Arouca Law, resulting in an increased focus, and rapid learning experience, on questions related to all aspects of animal experimentation. The law reinforces the idea that animal experiments must be based on ethical considerations and integritybased assumptions, and provides a regulatory framework to achieve this. This review describes the health research involving animals and the current Brazilian framework for regulating laboratory animal science, and hopes to help to improve the awareness of the scientific community of these ethical and legal rules.
\end{abstract}

Key words: animal use, biology, ethics, research.

\section{INTRODUCTION}

Animals have been used in studies and research for millennia in human history. Evidence shows that even in ancient Greece, Aristotle used animals in his studies, mainly to advance the understanding of living animals. But it was only during the $18^{\text {th }}$

Correspondence to: Monica Levy Andersen

E-mail: ml.andersen12@gmail.com

ORCid: http://orcid.org/0000-0002-1894-6748

* Contribution to the centenary of the Brazilian Academy of Sciences. and $19^{\text {th }}$ centuries that the development of animal models expanded, with many scientists, such as Jean Baptiste Van Helmont, Francesco Redi, John Needham, Lazzaro Spallanzani, Lavoisier and Pasteur, conducting animal experiments to study the origin of life (Oparin 1957).

In addition to being used to investigate the basic principles of life, animals were also used to develop a better understanding of animal and human anatomy, physiology, pathology and pharmacology. The possibility of experimenting under controlled situations and mimicking biological conditions 
of human and animal diseases reinforced the development of scientific methods and the creation of the concept of animal biological models.

Animal models have been responsible for the most important knowledge advances in many biological fields (Institute of Medicine and National Research Council 1988, 1991, Lieschke and Currie 2007). From Claude Bernard's classic study describing the role of the pancreas in digestion and the development of the oral live Polio virus vaccine by Albert Sabin, to the use of animals for the understanding of the pathogenicity of the Zika virus in the present day, animals have greatly contributed to scientific knowledge and improvements in quality of life. Animals have contributed to the development of new drugs and vaccines, as well as new surgical techniques and anesthesia protocols. Although there is some concern about extrapolating clinical relevance from animal data (Greek and Menache 2013), the progress made through the use of animal models is unquestionable, and nearly $90 \%$ of Nobel Prize research in Physiology and Medicine, used animal experiments in their discoveries.

To be used as a model, animal species must meet specific criteria in line with the final goal of the research. Many species are used in biomedical research, such as insects (Drosophila), nematodes (Caenorhabditis elegans), fish (Danio rerio, or zebrafish), frogs (Xenopus) and many mammals, such as mice, rats, dogs, cats, pigs and monkeys, due to their phylogenetic proximity to humans (Institute of Medicine and National Research Council 1991). Sometimes the model must be modified to meet specific characteristics: An interesting example is the development by Vivien Thomas and Alfred Blalock of a model that simulated the congenital heart defect tetralogy of Fallot (also known as the blue baby syndrome) in a dog. This model allowed the development of the surgical method that currently saves more than half a million children per year (Timmermans 2003). Nowadays, with the progress of genetic and genomic tools, genetic engineering techniques can easily be applied in order to develop knockout or transgenic animals that are used in research. Some of these constructs achieve the so-called "humanization" status through the graft of human cells that perform their primary functions in the recipient animal, allowing researchers to study responses to pathogens as if it were happening in a human environment (Ernst 2016). It is also important to emphasize that to obtain reliable results, the health quality of the animal used as a model is fundamental, and thus, it is in the interest of the researcher to have healthy and well treated animals.

\section{THE IMPORTANCE AND CHALLENGES OF ANIMAL BIOMEDICAL RESEARCH}

There is a dichotomy in the use of animals in translational research, especially research encompassing behavioral aspects: some studies produce promising results that could be applied to humans, while others fail to demonstrate any similarity between the animal model and the human condition

We will first describe a situation in which animal models have been shown to be extremely useful in unravelling the mechanisms of human physiology, and have given scientific support to new therapeutic approaches: the use of non-human primates as models in biomedical research. Nonhuman primates have been used in animal research due to their close phylogenetic relationship to humans, involving proven similarities in terms of genetics, behavioral and biochemical activities. The demand for the use of non-human primates as models in scientific research continues to grow, and some species continue to be considered important for several fields of research, such as the study of human diseases (AIDS, Parkinson's disease and hepatitis, among others), psychological and psychiatric disorders, toxicology, transplants, 
nutrition (including infant nutrition), dentistry, drug abuse and vaccine development. Animal research benefits not only humans, but also the animals themselves. For instance, animals, such as dogs and cats are living longer and healthier lives thanks to vaccines for rabies, parvo virus, tetanus and feline leukemia, among other breakthroughs made in Veterinary Medicine thanks to animal research.

Although the importance of the use of nonhuman primates in research continues to be critical to increasing our knowledge in many fields, a large bioethical discussion about the use of non-human primates in these studies has been taking place, especially regarding animals that are genetically closer to humans in the evolutionary scale, such as chimpanzees. After 2007, only the United States and Gabon continued using chimpanzees for research. In 2015, the United States passed a law classifying chimpanzees in captivity, including laboratory animals, as an endangered species. As a result, the National Institutes of Health (NIH), the main institution supporting research in the United States, has declared that it would no longer finance any research involving chimpanzees. The impact of this decision in the United States had major worldwide repercussions, leading to increased widespread discussion about the use of non-human primates for research. Activist groups in the United States welcomed this decision, and are now putting even more pressure on the United States government to end the use of non-human primates for scientific studies. However, the need for translational research is even stronger, and this process invariably requires experimental tests in non-human primates. With increasing pressure from lobby groups and some parts of the regulatory and funding systems, researchers have attempted to be more open about their animal studies and keen to promote dialog on the subject. The main objective has been to clarify the importance of non-human primate research and to make it evident that all procedures performed on experimental animals are conducted following rigorous scrutiny that guarantees that the studies are conducted to high ethical standards (Foundation for Biomedical Research 2016).

In Brazil, very little research with non-human primates is carried out compared to other countries, such as the United Kingdom and the United States. Even so, the National Council for the Control of Animal Experimentation (Conselho Nacional de Controle de Experimentação Animal - CONCEA) has been continuously updating policies related to the ethical demands for the use of primates in research. The public was invited to examine and comment on the standards proposed by CONCEA (Resolução Normativa 28 - CONCEA 13/11/2015) for the maintenance and use of non-human primates in Brazilian research. The process resulted in the publication, in November 2015, of the chapter: "The use of non-human primates in research and/ or education" (Primatas não humanos mantidos em instalações de instituições de ensino ou pesquisa científica) in the CONCEA Guide for use of Animals in Research or Education (Guia Brasileiro de Produção, Manutenção ou Utilização de Animais em Atividades de Ensino ou Pesquisa Científica) (http://www.mct.gov.br/upd_blob/0240/240230. pdf pgs 207-267). In all its other official documents, CONCEA continues to clearly state that the use of primates in research is restricted to situations in which there are no other available alternative methods of study.

Despite all the benefits that can arise from animal biomedical research, several studies show negative or inconsistent results. Animal models occasionally fail to reproduce the complexity of human behavioral disturbances, and have a limited ability to detect some effects (for review, see Kalueff et al. 2007). In addition, some of the results obtained from basic (animal) research are not found during clinical trials. This provides evidence against the principles of basic biomedical research: to generate 
knowledge that is useful and translationally relevant to the clinical arena. To the general public, this lack of clinical applicability in some studies can outweigh the increasing amount of research results that have life-saving implications, and leads to skepticism and the questioning of the value of animal research. In this regard, basic research meta-analysis can be an important tool in providing the full picture of the results of animal use, as it allows the translational validity of animal models to be properly assessed, and provides guidance for future studies which prevents experimental animals being used in ineffective models (Pires et al. 2016).

\section{ANIMAL MODELS FOR INFECTIOUS DISEASES STUDIES - PATHOGENICITY, DRUG TARGETING AND VACCINE APPROACHES}

It is important to understand the extent of pathogeneses and the mechanisms by which the infection is established for the development of vaccines. It is historically known that the first human vaccine, developed by the young British physician Edward Jenner, was a result of his observation of dairymaids who used to handle cows in the milking process. Jenner observed that because these women had had cowpox, they were never infected with smallpox. This inspired Jenner to inoculate the cowpox virus as a protective practice against smallpox (Riedel 2005). The Jenner vaccine was very important to mankind, and resulted in the eradication of smallpox. Therefore, the first vaccine was only possible due to the use of a living model. The work of Louis Pasteur in developing the rabies vaccine, for both dogs and humans, is another example of the efficiency of vaccination in protecting against virus-caused diseases.

In addition to viruses, bacteria can also be the etiological agent of many human or animal diseases. Antibiotic therapy has helped to control many of them, and, just like for viruses, protection and prevention from some bacteria-caused diseases can be obtained through vaccination. This practice is so efficient that the World Health Organization has produced a complete vaccination schedule for infants and adults against many biological agents: (http://www.who.int/immunization/policy/ immunization_tables/en/).

In the following section, we will give some examples on how animal models shed light onto the etiology of infections, leading to treatment, prevention and control protocols.

\section{HIV/AIDS}

Although vaccination is the best choice for controlling viruses, the development of a vaccine is not always easy or possible. In the end of the last century, one of the most remarkable and dramatic events in terms of public health was the advent of the acquired immunodeficiency syndrome (AIDS) epidemic that killed millions of people, especially in at-risk populations. With the lack of an efficient vaccine, the search for chemotherapy treatment for patients infected with human immunodeficiency virus (HIV) became urgent.

The major problem with HIV is its elevated human tissue tropism, making it difficult to model the condition in animals. The virus is not able to infect mice, rats, rabbits, or macaques, although it can replicate in chimpanzees (Victor Garcia 2016). Thus, initial efforts focused on the use of nonhuman primate models infected with a SIV (simian immunodeficiency virus), an HIV-like virus that infects Rhesus monkeys, producing clinical signals similar to human AIDS. Another non-human primate model used in efforts to refine and develop new treatments for AIDS and HIV infection, the sooty mangabey, is naturally infected with a strain of SIV and is the source of HIV-2, a less-virulent strain of HIV. This dual-model (virus/host) has been used to develop a better understanding of the pathogenesis of the virus in order to develop drugs and preventive strategies, such as the development of vaccines (Micci and Paiardini 2016). 
Antiretroviral treatments are now very effective in suppressing HIV replication. However, treatment interruption leads to a resurgence of AIDS. Thanks to non-human primate research on AIDS and HIV, a leading HIV/AIDS preventive vaccine is now licensed and in phase 2a human clinical trials. In addition to primate research, other animal models have been used to address the most relevant aspects of HIV infection, mostly virus persistence. First, humanized mice were obtained by transplantation of human cells or tissues in partially irradiated immune-deficient animals (Shultz et al. 2012). From this initial effort, different humanized mice models have been developed and are now being used to advance the HIV/AIDS field (Victor Garcia 2016).

\section{ZIKA VIRUS}

The Zika virus (ZIKV) is an RNA containing virus belonging to the Flaviviridae family, related to yellow fever, dengue and West Nile viruses. ZIKV originated from the Zika forest - Uganda, and was initially isolated from a yellow fever sentinel Rhesus monkey (Macaca mulatta) in 1947 (Dick et al. 1952). It was only isolated from a human in 1968 (Moore et al. 1975, Fagbami 1977), who clinically only presented fever. Artificially feeding Aedes aegypti mosquitoes on infected mice and monkeys confirmed that the transmission is made by the bite of mosquitoes from the Aedes genus (Boorman and Porterfield 1956).

Although the ZIKV was widely spread in Africa and Asia, the clinical aspects of the infection were considered mild, with a low incidence of human infection. However, in 2007 an outbreak of the infection occurred in Micronesia and patients presented fever, headache, anorexia, maculopapular rash, conjunctivitis, and arthralgia, but in all cases the clinical condition was, again, considered mild, self-limiting, and non-lethal (Lanciotti et al. 2008). In 2013, an Asiatic strain of ZIKV made its way to Brazil and became established in a large population of Aedes aegypti, a highly competent and anthropophilic vector species. This association produced an ongoing ZIKV epidemic in Brazil, with dramatic clinical consequences that correlated ZIKV infections and microcephaly cases (de Fatima Vasco Aragao et al. 2016).

To incontestably prove the correlation between ZIKV infection and microcephaly, Brazilian researchers chose the SJL mouse model, a strain defective in its ability to suppress T- cells (Hutchings et al. 1986) and notorious for its susceptibility to virus infections (Dahlberg et al. 2006). By infecting pregnant SJL females with a Brazilian ZIKV isolate, Cugola et al. (2016) demonstrated that the offspring presented clear signs of underdevelopment as well as a higher viral load in the brain when compared to mock-infected pups. Further investigation of ZIKVinfected mice brains showed cortex malformation with reduced cell number and cortical layer thickness. Those observations are consistent with human microcephaly (Cugola et al. 2016). Cugola et al. (2016) also used alternative cell cultures to correlate ZIKV-infection and microcephaly phenotype. ZIKV-infected human pluripotent stem cells derived from neural progenitor cells showed apoptotic cell death. Another alternative approach was the use of two-dimensional neural cell culture, neurospheres and cerebral organoids, that, when infected with ZIKV revealed cell death and a significantly smaller size compared to control cells. Furthermore, the use of tri-dimensional cerebral organoids derived from stem cells, simulating the first trimester of neurodevelopment in humans, also confirmed the reduction of cortical cells and the apoptotic phenotype. Infections of these tissues with the African strain of ZIKV did not show those signals, indicating that the Brazilian strain suffered a mutation/adaptation that led to the microcephaly condition (Cugola et al. 2016). In addition to the above described immunocompromised mice models, recently a study used the classical C57BL6 mice to 
show how an immunocompetent mammal activated the innate response and induced an antiviral $\mathrm{T}$ cell response in ZIKV infection. The study also showed a new epitope in the ZIKV envelope that is recognized by $\mathrm{CD} 8^{+} \mathrm{T}$ cell, an important finding for vaccines development (Pardy et al. 2017). Another study also using the immunocompetent C57BL6 showed windows, that could be correlated to human embryogenesis when infection caused the congenital abnormalities that result the microcephaly picture (Xavier-Neto et al. 2017).

Beyond the understanding of the pathophysiology of ZIKV infection, animal models are also being used for the development of therapeutic targets and vaccines for the control and prevention of ZIKV infections. Larocca et al. (2016) achieved immunity protection against the Brazilian ZIKV in mice models using different vaccination protocols (ZIKV DNA-based vaccine and purified formalin inactivated virus vaccine). The authors also showed that the protection could be achieved against the Puerto Rico ZIKV isolate as well. The same research group also observed promising results with the two immunization protocols in Rhesus monkeys (Abbink et al. 2016). The efforts in achieving an effective vaccination protocol has led the Butantan Institute in São Paulo (BR) to concentrate their efforts on the production of the DNA vaccine, with a promise of getting to a first round of human tests in 2017.

\section{CHIKUNGUNYA VIRUS}

Another important virus that is currently a subject of public health concern in Brazil is the Chikungunya virus (CHIKV). It is a Togaviridae RNA virus also transmitted by Aedes bites. The symptoms of acute infection in humans (i.e. fever, headache, myalgia, fatigue and polyarthalgia), although painful, resolve in a few days. The most prominent problem is the recurrent appearance of arthralgia that might compromise the quality of life of the affected individual (Couturier et al. 2012, Schilte et al. 2013). The chronic symptoms are due to the ability of the virus to replicate in joint tissues and muscle cells. Despite the global spread of the virus, affecting millions of patients, its pathogenesis is still unknown. This emphasizes the fact that animal models related to viral replication are still warranted in order to promote the understanding of the immunological responses that can lead to the development of drugs and vaccines (Ozden et al. 2007).

Mice present many advantages as models for CHIKV infection. In addition to the low cost and ease of maintenance, the existence of a large panel of commercial antibodies, established lineages that provide colonies with the same genetic background, and the possibility of choosing genetically modified animals has led researchers to study the CHIKV in mouse models. These studies have investigated acute infections, lethal neonatal challenges, immune-commitment, as well as the main clinical signs of infection, such as arthritis, myositis and chronic development of peripheral joint lesion and muscle pain (Haese et al. 2016).

In addition to mice models, CHIKV is also being investigated using the old world monkey group belonging to the genus Macaca, such as the Rhesus (M. mulatta), Bonet ( $M$. radiate) and Cynomolgus (M. fascicularis) monkeys (Haese et al. 2016). The macaque model is especially relevant to the study of CHIKV pathogenesis and the efficacy of drugs and vaccines.

\section{EUKARYOTIC PATHOGENS}

The list of viruses or bacteria involved in human diseases is long: here we give a few examples on how animal models have been used to understand virus/host interactions and provide solutions, such as treatments and prevention strategies.

The study and development of preventive tools for eukaryotic organisms is particularly 
problematic. The higher level of complexity in these organisms besides the many mechanisms they employ for evading host responses have made it impossible to develop effective vaccines for eukaryotic organisms. This highlights the relevance of animal models that can lead to a better understanding of the host/pathogen relationship, and ultimately ways to control these infectious agents.

In the early 1900's, Carlos Chagas, a bright young Brazilian physician and researcher, described the etiological agent as well as the mode of transmission of Chagas' disease using an animal model. Chagas was in a small town in the countryside of Minas Gerais (later named Lassance, after the engineer Ernesto Lassance Cunha) working on a campaign against malaria during the construction of an extension of the Central do Brazil Railroad. Chagas had an interest in research, and used to collect and examine the local fauna. Examining a blood sample of a marmoset (Callithrix penicillata), he noticed the presence of a protozoan of the Trypanosomatidae family. At that time, similar organisms had been implicated in the cattle disease Nagana as well as in human sleeping sickness in Africa. Thus, Chagas took a careful look at that organism and described a new species, named Trypanosoma minasense. At the same time, Chagas was alerted by another engineer, Cornélio Cantarino Mota, to the presence in the region of a hematophagous bug known as "barbeiro" (barber bug or kissing bug) from the Triatominae family. Chagas collected and dissected some of these insects and, in the digestive tract of the bugs, found protozoan forms that he initially thought to be T. minasense in another stage of the life cycle. Chagas sent some live bugs to the Instituto Manguinhos (now, Instituto Oswaldo Cruz/RJ) and asked Oswaldo Cruz to feed marmosets kept under clean conditions with the insects. Subsequently, flagellates were detected in the controlled marmoset blood. Back in Manguinhos, Chagas then examined the flagellate samples and realized that it was not T. minasense, but another new species he called T. cruzi after his mentor Oswaldo Cruz. Suspecting that the parasite could also infect humans, Chagas went back to Lassance and started to examine the blood of patients, finally connecting the presence of T.cruzi with the symptomatology of Chagas' disease. It is remarkable to note that this classic demonstration of the etiological agent of a disease, as well as of the transmission cycle and identification of possible vectors and reservoirs, took place in early 1900's.

Although enormous progress has been made in the understanding of the relationship between $T$. cruzi and the host, few drugs have been developed for the treatment of Chagas' disease to date and no vaccines. All treatments available for the disease are a result of studies that essentially used animal models.

Leishmania is another protozoan responsible for a re-emergent disease in Brazil and in other regions of the world. Leishmaniasis consists of a complex framework of clinical signs. The World Health Organization estimates a worldwide prevalence of 12 million cases of leishmaniasis, with an annual mortality of 60,000 people and an at-risk population of approximately 350 million people in 88 countries around the world (http:// www.who.int/leishmaniasis/burden/en/).

Leishmania is also transmitted by an insect bite in this case the vectors are sandflies belonging to the Psychodidae family. Many mammal species can harbor the parasite. Sylvatic mammals constitute reservoirs for the disease, complicating the epidemiological control. Domestic animals, like horses, cats and mainly dogs are infected and contribute to the transmission to humans.

In the mammal host, Leishmania is an obligate intra-cellular parasite found mainly in macrophages which, together with monocytes, constitute the body's phagocyte system. To survive and replicate in this defense cell, the parasite 
evades the humoral immune response against Leishmania produced by the host, by residing within the phagocytosomes of the macrophages. One of the strategies used to fight against invaders is the activation of oxidative burst, induced with the phagocytosis of these organisms (Cunningham 2002). Nitric oxide synthase 2 (NOS2) is also a very important enzyme in macrophage response, and when activated produces citrulline and nitric oxide (NO) from the oxidation of L-arginine: NO is a highly reactive, effector molecule which can combat invasive microorganisms (Qadoumi et al. 2002). Thus, a good animal model to be used in Leishmania studies must fulfill all these features.

The chosen model uses inbred mice, specifically, the resistant $\mathrm{C} 57 \mathrm{BL} / 6$ that produces a $\mathrm{T}$ helper (Th) 1 immune response and the BALB/c susceptible mice that produces a Th2 response (Sacks and Noben-Trauth 2002). The Th1 response promotes NOS2 activation and NO production (Bogdan 2001) and the Th2 response is associated with the production of IL-4 and IL-13 (Sacks and Noben-Trauth 2002). In respect to NO production, the amino acid arginine was shown to be a key molecule in the success or failure of the parasite in establishing the infection. In addition to being a substrate of NOS2, arginine can also be used by arginase I to produce urea and ornithine, the last being precursor of the polyamines involved in the replication of the parasite. It is interesting to note that in a $\mathrm{Th} 2$ response, arginase $\mathrm{I}$ is also activated. Leishmania itself presents arginase activity, and in a construction of a parasite with the arginase knocked out, it was possible to show that Leishmania arginase is related to parasite replication and survival (da Silva et al. 2012, da Silva and Floeter-Winter 2014).

In relation to $\mathrm{NO} /$ ornithine physiological duality, it is interesting to note that the healing of human cutaneous leishmaniasis is associated with a Th1 response (Alexander and Bryson 2005), corroborating the observation of the mice model.
However, in humans, the participation of NO in killing the parasite is still an open question, which has been addressed with the use of "humanized" mice such as the NSG strain that does not have B and $\mathrm{T}$ cells from mice, and also presents a higher rate of engraftment with human hematopoietic cells (Wege et al. 2012).

As already mentioned in this review, it is important that the appropriate model is used to provide the required conditions to answer a specific scientific question. This was the case in a study to understand the physiological role of the "darkness hormone" melatonin in Leishmania infection. The best animal model for melatonin studies is the rat model, but rats are refractory to Leishmania infection. The best model for Leishmania study is the mice model, but mice are too small for sample collection to analyze melatonin effects. Hence, Laranjeira-Silva et al (2015) validated a hamster model in the case of melatonin/Leishmania. The results of this research showed that melatonin impairs Leishmania infection, pointing to potential new treatments, as well as indicating a possible explanation of why sylvatic mammals do not develop disease signs, because, being nocturnal animals, they are infected during the night when they present high levels of melatonin in the bloodstream.

\section{ETHICAL CONCERNS ON THE USE OF ANIMALS IN BIOLOGICAL RESEARCH}

Based on the above examples, one can understand how difficult it is to conduct animal research. It is important to note that beyond adequate technical knowledge, animal experimentation requires that ethical concerns speak louder than scientific interests. Each researcher must have a complete understanding of the animal model being used, and of the biology and behavior of that species. Researchers must also be aware of the importance of the work being conducted, and consider all the 
premises that justify each specific project based on a solid scientific background (see Andersen and Tufik 2010, Andersen and Helfenstein 2015).

Animal experimentation has incited a great deal of debate, with a lot of the discussion focusing on ethical considerations. The British parliament was pioneer in enacting laws regarding the use of animals in research (http://web.archive.org/ web/20061214034848/http://homepage.tinet. ie/ p pnowlan/Chapter-77.htm). In 1876 it introduced the Cruelty to Animals Act, which amended the previous 1849 Act, and included regulation of animal experimentation. The act highlighted three main points: 1. animal experiments should only be carried out when there is absolute need of knowledge that will be useful for saving or prolonging life or alleviate suffering; 2 . the animals must be anesthetized; and 3. the animals must be killed immediately after the experimental procedure if they would be injured or in pain as a result of the experiment.

The Principle of the 3R's also emerged from the United Kingdom. A young zoologist, William Russell, who also worked as a psychologist, and Rex Burch, a microbiologist that introduced ethical aspects in laboratory techniques, produced a report that was later published as a book with the first description of the 3R's Principle (Russel and Burch 1959). Each $\mathbf{R}$ stands for a principle for the ethical use of animals in experiments: Reduction is the application of methods that allow a reduced number of animals to be used in a protocol. This can be achieved by detailed planning of the experiments, guaranteeing that results will have statistical significance. The use of animals presenting the same or a similar genetic background also ensures a low fluctuation of the data, thereby reducing the number of animals which need to be used in a study. Many websites are available to access statistical methods that allow an accurate calculation of the number of animals to be used in an experiment (for example see https://www.nc3rs.org.uk/experimental- designstatistics). Nowadays, access to several available data-bases (meta-analysis) sometimes allows the number of animals used to be reduced or in some cases allows their use to be avoided completely. Refinement consists in the application of methods that avoid animal suffering, such as: the use of anesthesia during a procedure and analgesic regimens for pain relief during recovery; the use of non-invasive techniques; housing conditions that provide a comfortable and safe environment and training the animal to cooperate with procedures. Replacement is the major goal for the use of animals in science. It consists of the substitution of animals with other models, such as microorganisms or other invertebrates, cell cultures, organs or even cellular fractions. The ideal replacement would be a protocol conducted with no use of animals.

The 3R's Principles are now universal, and guide animal research in many countries. There is a growing commitment of the scientific community to the implementation of the Principles of RussellBurch (Russel and Burch 1959) of "reduction, replacement and refinement" in the use of experimental animals.

In 2010, as initiative of the National Centre for the Replacement, Refinement and Reduction of Animals in Research (NC3Rs), the ARRIVE (Animal Research: Reporting of In Vivo Experiments) guidelines were published and are currently endorsed by scientific journals and by funding agencies, and others. The ARRIVE guidelines that has been translated in several languages have a checklist of 20 items relating information, such as the number and specific characteristics of animals used (e.g. species, sex, strain, genetic background); housing and husbandry; and the experimental, statistical, and analytical methods. The goals are to improve the design, analysis and reporting of research using animals maximizing information published and minimizing unnecessary studies, as pointed out by Kilkenny et al. (2010). Collectively, 3Rs, 
ARRIVE guidelines and additional initiatives are marked efforts to accomplish ethical background in biomedical research.

\section{BRAZILIAN LEGISLATION ON THE USE OF ANIMALS IN BIOLOGICAL RESEARCH}

Due to the efforts of the physician and researcher Sergio Arouca, in 2008, after lengthy discussion in the Brazilian National Congress, Brazil emerged into a new era of animal research regulation with the promulgation of Law $\mathrm{n}^{0} .11794 / 2008$, previously known as the Arouca Law. This law established the Conselho Nacional de Controle de Experimentação Animal (CONCEA) and regulates Ethical Committees on Animal Use (CEUAs), which are responsible for regulating animal use in education and scientific research purposes. CEUAs have the role of encouraging ethical thinking and appreciation for the concept of animal welfare, as well as to promote the development of alternative measures to the use of animals in research or practical classes.

According to the law, all projects involving laboratory animals must be submitted and reviewed by an institutional CEUA, which has the authority to halt any teaching or research practice that does not comply with the legislation. The CEUAs are formally responsible for the care and use of research and teaching-purpose animals within the institution, and must ensure that facility standards and the care of animals are in accordance with CONCEA resolutions.

After the creation of the Law $n^{\circ} .11794 / 2008$ and corresponding Decree, $n^{\circ}$. 6899/2009, Brazil embarked on a long ethical and learning journey in relation to animal experimentation. We are certainly in need of programs and training courses to better prepare our students, technicians and researchers to work with laboratory animals. The teaching of Laboratory Animal Science is recent in our academic scenario, but there is a range of pedagogic materials available in different spheres, being provided by the government or available in the international literature. Brazil has reached a position of importance in the scientific community through scientific publications, and it is important that Brazil works to international norms in terms of animal experimentation so that it can continue to make major contributions to the global scientific community. Thus, we expect that not only will universities and research centers throughout the country work to the standards outlined in the current legislation, but also that further initiatives will be introduced in future, including the consolidation of research from different centers across the country. We have now established an ethical standard and specific rules for animal protection and the promotion of animal well-being in Brazil.

\section{APPROACH TO ALTERNATIVE METHODS}

Alternative methods can improve and strengthen the production of scientific knowledge while fulfilling one of the Principles of the 3R's (Replacement). The specific advantages of the use of alternative non-animal methods are: 1 . Models may be used more than once, by several people, independently of time and place of study; 2 . The use of alternative models allows students to self-evaluate until they reach the aimed learning objectives; 3 . Alternative methods which use modern video and computer techniques, such as 3D technology, can allow the demonstration of physiological phenomena that are impossible to visualize in animal models (e.g. animations of cells and organ function); 4. The cost of implementation of alternative methods may initially be high, but in a near future may reduce costs in terms of the acquisition, transport and maintenance of animals (Van der Valk et al. 1999).

From the teaching point of view, there is a marked emphasis from CONCEA on the replacement of animals by alternative methods in classes. The "Symposium of Alternative Methods 
to the Use of Animals in Teaching", sponsored by CONCEA/MCTIC in 2016, had as its main goal the presentation of alternative methods that are were being used in Brazil, and to increase the pedagogical development of similar activities in teaching classes. The symposium resulted in wider knowledge dissemination and a marked increase in the discussion of pedagogical methods for practical teaching in the areas of biology, biomedicine, health and veterinary, among others.

In February 2016, CONCEA published in the Union Official Diary the Brazilian Directive for the Care and Use of Animals in Teaching or Scientific Research Activities (Diretriz Brasileira para o Cuidado e a Utilização de Animais em Atividades de Ensino ou de Pesquisa Científica - DBCA). This directive addresses institutional responsibility in promoting the use of alternative methods for students and the so-called "Conscious Objection", which now holds legal and ethical power. CONCEA has established that institutions involved in animal experimentation have a legal responsibility to provide alternative methods for "Conscious Objectors" (i.e., students that oppose to the use of animals for teaching purposes), and to provide support for those students. That was a fundamental step towards more modern pedagogical practices, aiming the students' interests without compromising the learning process.

Alternative methods have also become an exceptional ally in the reduction of the unnecessary use of animals in practical classes. In addition to being introduced to a major control and research quality based on ethical legislations, students frequently return motivated from international experiences during which they experienced appropriate learning in accordance with educational and pedagogical propositions without the use of animals. Thus, students who study abroad will become familiar with non-animal methods before they come back to Brazil and that might encourage
Brazilian institutions to start looking for alternative methods.

From the research point of view, in addition to the improvements being made in the development of better animal models, a great deal of effort is being dedicated to finding alternative approaches to the use of animals: Plants, such as Arabdopis taliana, can be used as models organisms in biological research. In addition, cell cultures, in vitro approaches, the use of stem cells for differentiation and regeneration, as well as advances in the use of tools such as intravital microscopy, magnetic resonance imaging (MRI) or positron emission tomography (PET) (Lieschke and Currie 2007) scans and progress in informatics such as increased use of meta-analysis (Greek and Menache 2013) have all resulted in a substantial reduction of the number of animals used in research.

Three bodies have been established in Brazil to oversee the processes of validation of alternative methods. They are:

BRACVAM: The Brazilian Center for Validation of Alternative Methods - identifies the need to validate a method, organizes the peerreview process and provides evidence of the scientific validity of a method to CONCEA;

RENAMA: National Network of Alternative Methods - A network of laboratories which execute the validation;

CONCEA: Created by Law $n^{\circ} .11794 / 2008$, is the official council for alternative scientific methods in Brazil. Since 2014, it has already recognized 24 scientifically validated and internationally accepted test methods (e.g. skin corrosion/irritation, etc.). Altogether, these bodies aim to produce reliable information on the applicability of alternative methods and the benefits that may arise from the use of these methods by researchers and students/ professors.

Several regulations published by CONCEA, deal with the regulation of alternative methods. It must be pointed out that, in addition to CONCEA, 
ANVISA (Agência Nacional de Vigilância Sanitária) has also produced regulations in this area: RDC 35/2015. The participation of members of Animal Protection Societies in CONCEA reinforces the debate on the use of animals for research, the consideration of alternative methods and the demands of our modern society.

\section{CONCLUSIONS}

This article aims to describe and contextualize animal models and the evolution of Laboratory Animal Science. The relevance of animals for the development of Veterinary and human health is undeniable. According to rules and laws imposed by the government, research projects must be within the parameters previously established for teaching or research purposes. The use of animals in experiments must be primarily anchored in ethical and integrity-based assumptions, and most certainly must justify the use of animal.

Most citizens, regardless of their background, are concerned with the well-being of animals, while wishing to see the continued development of drugs for the treatment of disease and the maintenance of quality of life. This text provides a useful tool to demonstrate to the academic community and the wider public the progress which has been made nationally in the search for excellence in the use of animals in research and teaching activities, and the benefits that animal research provides to human beings.

Those who pursue academic goals using animal research must do so based on ethical principles and with dedication under the parameters that regulate laboratory practices. Each researcher must make every effort to employ animals in academic activities in the most ethical and responsible way, while contributing to knowledge dissemination and not forgetting the principles of the legislation.

As authors and scientists, we invite Society to be part of a wider forum, promoting reflection on, and integrity in the use of animals in science. We call on the academic community to follow the ethical and legal rules approved by the entire nation: Together, we can make scientific advances that will improve the quality of life of all citizens, while at the same time reducing the number of animals used in research and providing better treatment and conditions for the laboratory animals that continue to be used.

\section{ACKNOWLEDGMENTS}

The authors receive fellowships from the Conselho Nacional de Desenvolvimento Científico e Tecnológico (CNPq): 305177/2013-3 (MLA) and 307587/2014-2 (LMFW). The authors also thank Associação Fundo de Incentivo a Pesquisa (AFIP).

\section{REFERENCES}

ABBINK P ET AL. 2016. Protective efficacy of multiple vaccine platforms against Zika virus challenge in rhesus monkeys. Science 353: 1129-1132.

ALEXANDER J AND BRYSON K. 2005. T helper (h)1/Th2 and Leishmania: paradox rather than paradigm. Immunol Lett 99: 17-23.

ANDERSEN ML AND HELFENSTEIN T. 2015. Guia prático da legislação vigente sobre experimentação animal CEUA/ UNIFESP. UNIFESP, Ebook http://www.unifesp.br/ reitoria/ceua/.

ANDERSEN ML AND TUFIK S. 2010. Animal models as ethical tools in biomedical research. São Paulo Universidade Federal de São Paulo-UNIFESP/EPM, São Paulo, Brazil, 563 p.

BOGDAN C. 2001. Nitric oxide and the immune response. Nat Immunol 2: 907-916.

BOORMAN JP AND PORTERFIELD JS. 1956. A simple technique for infection of mosquitoes with viruses; transmission of Zika virus. Trans R Soc Trop Med Hyg 50: $238-242$.

BRAZIL. 2008. Lei No 11.794 , de 8 de outubro 2008. http:// www.planalto.gov.br/ccivil_03/_Ato2007-2010/2008/Lei/ L11794.htm

BRAZIL. 2009. Decreto No 6.899, 15 de julho de 2009. http:// www.planalto.gov.br/ccivil_03/_Ato2007-2010/2009/ Decreto/D6899.htm

CONCEA - CONSELHO NACIONAL DE CONTROLE DA EXPERIMENTAÇÃO ANIMAL. 2015. Normativas do CONCEA para produção, manutenção ou utilização de 
animais em atividades de ensino ou pesquisa científica. Brasília, Brazil, 221 p. (http://www.mct.gov.br/upd blob/0240/240230.pdf).

COUTURIER E, GUILLEMIN F, MURA M, LEON L, VIRION JM, LETORT MJ, DE VALK H, SIMON F AND VAILLANT V. 2012. Impaired quality of life after chikungunya virus infection: a 2-year follow-up study. Rheumatology (Oxford) 51: 1315-1322.

CUGOLA FR ET AL. 2016. The Brazilian Zika virus strain causes birth defects in experimental models. Nature 534: 267-271.

CUNNINGHAM AC. 2002. Parasitic adaptive mechanisms in infection by leishmania. Exp Mol Pathol 72: 132-141.

DAHLBERG A, AUBLE MR AND PETRO TM. 2006. Reduced expression of IL-12 p35 by SJL/J macrophages responding to Theiler's virus infection is associated with constitutive activation of IRF-3. Virology 353: 422-432.

DA SILVA MFL AND FLOETER-WINTER LM. 2014. In: Santos ALS, Branquinha MH, d'Avila-Levy CM, Kneipp LF and Sodré CL (Eds), Arginase in Leishmania. Proteins and Proteomics of Leishmania and Trypanosoma. Dordrecht: Springer Netherlands, p. 103-117.

DA SILVA MFL, ZAMPIERI RA, MUXEL SM, BEVERLEY SM AND FLOETER-WINTER LM. 2012. Leishmania amazonensis Arginase Compartmentalization in the Glycosome Is Important for Parasite Infectivity. PLoS ONE 7: e34022.

DE FATIMA VASCO ARAGAO M, VAN DER LINDEN V, BRAINER-LIMA AM, COELI RR, ROCHA MA, SOBRAL DA SILVA P, DURCE COSTA GOMES DE CARVALHO M, VAN DER LINDEN A, CESARIO DE HOLANDA A AND VALENCA MM. 2016. Clinical features and neuroimaging (CT and MRI) findings in presumed Zika virus related congenital infection and microcephaly: retrospective case series study. BMJ 353: i1901.

DICK GW, KITCHEN SF AND HADDOW AJ. 1952. Zika virus. I. Isolations and serological specificity. Trans R Soc Trop Med Hyg 46: 509-520.

ERNST W. 2016. Humanized mice in infectious diseases. Comp Immunol Microbiol Infect Dis 49: 29-38.

FAGBAMI A. 1977. Epidemiological investigations on arbovirus infections at Igbo-Ora, Nigeria. Trop Geogr Med 29: 187-191.

FOUNDATION FOR BIOMEDICAL RESEARCH. 2016. The Critical Role of Nonhuman Primates in Medical Research, New York, NY.

GREEK R AND MENACHE A. 2013. Systematic reviews of animal models: methodology versus epistemology. Int $\mathrm{J}$ Med Sci 10: 206-221.

HAESE NN, BROECKEL RM, HAWMAN DW, HEISE MT, MORRISON TE AND STREBLOW DN. 2016. Animal
Models of Chikungunya Virus Infection and Disease. J Infect Dis 214: S482-S487.

HUTCHINGS PR, VAREY AM AND COOKE A. 1986. Immunological defects in SJL mice. Immunology 59: 445450 .

INSTITUTE OF MEDICINE AND NATIONAL RESEARCH COUNCIL. 1988. Use of Laboratory Animals in Biomedical and Behavioral Research. Washington, DC: The National Academies Press, Washington, USA.

INSTITUTE OF MEDICINE AND NATIONAL RESEARCH COUNCIL. 1991. Science, Medicine, and Animals. Washington, DC: The National Academies Press, Washington, DC, USA.

KALUEFF AV, WHEATON M AND MURPHY DL. 2007. What's wrong with my mouse model? Advances and strategies in animal modeling of anxiety and depression. Behav Brain Res 179: 1-18.

KILKENNY C, BROWNE WJ, CUTHILL IC, EMERSON M AND ALTMAN DG. 2010. Improving bioscience research reporting: the ARRIVE guidelines for reporting animal research. PLoS Biol 8(6): e1000412.

LANCIOTTI RS, KOSOY OL, LAVEN JJ, VELEZ JO, LAMBERT AJ, JOHNSON AJ, STANFIELD SM AND DUFFY MR. 2008. Genetic and serologic properties of Zika virus associated with an epidemic, Yap State, Micronesia, 2007. Emerg Infect Dis 14: 1232-1239.

LARANJEIRA-SILVA MF, ZAMPIERI RA, MUXEL SM, FLOETER-WINTER LM AND MARKUS RP. 2015. Melatonin attenuates Leishmania (L.) amazonensis infection by modulating arginine metabolism. J Pineal Res 59: 478-487.

LAROCCA RA ET AL. 2016. Vaccine protection against Zika virus from Brazil. Nature 536: 474-478.

LIESCHKE GJ AND CURRIE PD. 2007. Animal models of human disease: zebrafish swim into view. Nat Rev Genet 8: 353-367.

MICCI L AND PAIARDINI M. 2016. Editorial overview: Animal models for viral diseases. Curr Opin Virol 19: ix$\mathrm{xi}$.

MOORE DL, CAUSEY OR, CAREY DE, REDDY S, COOKE AR, AKINKUGBE FM, DAVID-WEST TS AND KEMP GE. 1975. Arthropod-borne viral infections of man in Nigeria, 1964-1970. Ann Trop Med Parasitol 69: 49-64.

OPARIN AI. 1957. The Origin of Life on the Earth. New York: Academic Press, New York, USA.

OZDEN S ET AL. 2007. Human muscle satellite cells as targets of Chikungunya virus infection. PLoS One 2: e527.

PARDY RD, RAJAH MM, CONDOTTA AS, TAYLOR NG, SAGAN SM AND RICHER MJ. 2017. Analysis of the T Cell Response to Zika Virus and Identification of a Novel $\mathrm{CD}^{+} \mathrm{T}$ Cell Epitope in Immunocompetent Mice. PLoS Pathog 13: e1006184. 
PIRES GN, BEZERRAAG, TUFIK S AND ANDERSEN ML. 2016. Effects of experimental sleep deprivation on anxietylike behavior in animal research: Systematic review and meta-analysis. Neurosci Biobehav Rev: 68: 575-589.

QADOUMI M, BECKER I, DONHAUSER N, ROLLINGHOFF M AND BOGDAN C. 2002. Expression of inducible nitric oxide synthase in skin lesions of patients with american cutaneous leishmaniasis. Infect Immun 70: 4638-4642.

RIEDEL S. 2005. Edward Jenner and the history of smallpox and vaccination. Proceedings (Baylor University. Medical Center) 18: 21-25.

RUSSEL WMS, BURCH RL. 1959. The principles of humane experimental techniques. London: Methuen, London, UK.

SACKS D AND NOBEN-TRAUTH N. 2002. The immunology of susceptibility and resistance to Leishmania major in mice. Nat Rev Immunol 2: 845-858.

SCHILTE C, STAIKOWSKY F, COUDERC T, MADEC Y, CARPENTIER F, KASSAB S, ALBERT ML, LECUIT M AND MICHAULT A. 2013. Chikungunya virus-associated long-term arthralgia: a 36-month prospective longitudinal study. PLoS Negl Trop Dis 7: e2137.
SHULTZ LD, BREHM MA, GARCIA-MARTINEZ JV AND GREINER DL. 2012. Humanized mice for immune system investigation: progress, promise and challenges. Nat Rev Immunol 12: 786-798.

TIMMERMANS S. 2003. A Black Technician and Blue Babies. Social Studies in Science 33: 32.

VAN DER VALK J. 1999. Alternatives to the Use of Animals in Higher Education: The Report and Recommendations of ECVAM (European Centre for the Validation of Alternate Methods) Workshop 33. Altern Lab Anim. 27: 39-52.

VICTOR GARCIA J. 2016. Humanized mice for HIV and AIDS research. Curr Opin Virol 19: 56-64.

WEGE AK, FLORIAN C, ERNST W, ZIMARA N, SCHLEICHER U, HANSES F, SCHMID MAND RITTER U. 2012. Leishmania major infection in humanized mice induces systemic infection and provokes a nonprotective human immune response. PLoS Negl Trop Dis 6: e1741.

XAVIER-NETO J ET AL. 2017. Hydrocephalus and arthrogryposis in an immunocompetent mouse model of ZIKA teratogeny: A developmental study. PLoS Negl Trop Dis 11: e5363. 